Hydrology and Earth System Sciences, 5(4), 563-568 (2001) C $\quad$ EGS

\title{
The HYDROMED model and its application to semi-arid Mediterranean catchments with hill reservoirs 3: Reservoir storage capacity and probability of failure model
}

\author{
R. Ragab, B. Austin and D. Moidinis \\ Centre for Ecology and Hydrology, Wallingford, OX10 8BB, UK \\ E-mail for corresponding author: Rag@ceh.ac.uk
}

\begin{abstract}
This paper addresses the issue of "what reservoir storage capacity is required to maintain a yield with a given probability of failure? ". It is an important issue in terms of construction and cost. HYDROMED offers a solution based on the modified Gould probability matrix method. This method has the advantage of sampling all years data without reference to the sequence and is therefore particularly suitable for catchments with patchy data. In the HYDROMED model, the probability of failure is calculated on a monthly basis. The model has been applied to the El-Gouazine catchment in Tunisia using a long rainfall record from Kairouan together with the estimated Hortonian runoff, class A pan evaporation data and estimated abstraction data. Generally, the probability of failure differed from winter to summer. Generally, the probability of failure approaches zero when the reservoir capacity is $500,000 \mathrm{~m}^{3}$. The $25 \%$ probability of failure $(75 \%$ success) is achieved with a reservoir capacity of $58,000 \mathrm{~m}^{3}$ in June and $95,000 \mathrm{~m}^{3}$ in January. The probability of failure for a $240,000 \mathrm{~m}^{3}$ capacity reservoir (closer to storage capacity of El-Gouazine 233, $000 \mathrm{~m}^{3}$ ), is approximately $5 \%$ in November, December and January, $3 \%$ in March, and $1.1 \%$ in May and June. Consequently there is no high risk of El-Gouazine being unable to meet its requirements at a capacity of $233,000 \mathrm{~m}^{3}$. Subsequently the benefit, in terms of probability of failure, by increasing the reservoir volume of El-Gouazine to greater than the $250,000 \mathrm{~m}^{3}$ is not high. This is important for the design engineers and the funding organizations. However, the analysis is based on the existing water abstraction policy, absence of siltation rate data and on the assumption that the present climate will prevail during the lifetime of the reservoir. Should these conditions change, a new analysis should be carried out.
\end{abstract}

Keywords: HYDROMED, reservoir, storage capacity, probability of failure, Mediterranean

\section{Introduction}

As water resources become limited while population is growing in the arid and semi-arid regions, there will always be a need to develop more water resources. Rainfall harvesting in coastal areas into mountain reservoirs could be an important water resource in such drought prone regions, (Prinz, 1995). There are two aspects to building reservoirs, the capacity and the operation. The design of a reservoir is concerned with determining the storage capacity required to maintain a yield with a given probability of failure. This is very important as the cost of building the reservoir increases exponentially with the height of the dam. On the other hand a reservoir, which is too small, will not serve its purpose and there will be a shortage of water on a regular basis. A sound management should strike a balance between costs of building, net gain from having the reservoir (in financial or social terms) and the probability of failure (and cost of failure).

Design and operation of a reservoir are closely linked. Both aspects have been discussed by several researchers. Operation strategies have been discussed in several publications. Morel-Seytoux (1999) developed a methodology for optimum operation on a day-to-day basis for a system of several reservoirs with objectives to be satisfied at each target point. Tate and Farquharson (2000) tried several options of possible operation strategies for the Tarbela reservoir on the river Indus. Tedd et al. (1998) investigated internal erosion, while Atkinson (1998) discussed reservoir operation to control sediments. Vedula and Kumar (1996) developed an integrated model for 
optimal operation for irrigation of multiple crops. Meigh (1995) studied the impact of small farm reservoirs on urban water supplies in Botswana.

Several methods are available for reservoir storage-yield design but they rely on long inflow sequences, which are often scarce in arid and semi-arid regions. A large number of reservoirs has been designed and constructed in such low rainfall, high evaporation rate areas. In such cases, reliable estimates of inflows are particularly important as water losses by evaporation and seepage will often exceed the abstractions because the reservoir yield results are very sensitive to input data. Most of the literature refers to three broad methods for the design procedure (Parks and Gustard, 1982). The first method is the "critical period technique" which is an analysis of the events where yield exceeds demand. The second method is the "probability matrix method" where the probability of the reservoir reaching a given storage condition from a previous condition is analysed. The third method uses stochastically generated flow data for assessing the error in estimating the capacity. These methods are described in detail in McMahon and Mein (1978).

In semi-arid regions, high evaporation rates and low, sporadic rainfall make the calculations more difficult (and important) and, as with any statistical analysis, a lack of data results in a lack of confidence in the results. In reservoir terminology a "critical period" is the period during which the reservoir goes from full to empty. The critical period technique for reservoir yield analysis involves the use of the historical inflow record and the projected demand to simulate the volumetric behaviour of the reservoir. The method uses the mass storage equation and requires the historical inflows, outflows (including evaporation, spillage and any other losses) and an assumed active storage capacity (Eqn. 1).

$$
\mathrm{V}(\mathrm{t}+1)=\mathrm{V}(\mathrm{t})+\mathrm{Q}_{\text {in }}(\mathrm{t})-\mathrm{Abs}(\mathrm{t})-\Delta \mathrm{E}(\mathrm{t})-\mathrm{D}(\mathrm{t})
$$

where $\mathrm{Q}_{\text {in }}(\mathrm{t})$ is the inflow, $\operatorname{Abs}(\mathrm{t})$ is the abstraction pattern, $\Delta \mathrm{E}(\mathrm{t})$ is the evaporation and $\mathrm{D}(\mathrm{t})$ are reservoir releases, $\mathrm{t}$ is time and $\mathrm{V}$ is reservoir volume. Any other inflows or outflows are easily incorporated as needed.

Provided that a sufficiently long record is available, the simulation is run and the numbers of failures (reservoir becoming empty) are counted. The simulation is then rerun using a different active storage assumption or demand scenario until an acceptable balance is achieved between active storage required, demand and probability of failure.

The Moran probability matrix method (Moran, 1959) treats time and water as discrete variables. The reservoir volume is subdivided into a number of zones thus creating a system of equations, which approximate integral equations. The analysis is then carried out with the initial reservoir contents at each of the zones and using each year of input data thus making use of all available data. In this method, the period of time is divided into a wet season (all inflows, no outflows) followed by a dry season (all outflows, no inflows), though a simple modification of this procedure (Gould, 1961, McMahon and Mein, 1978) allows inflows and outflows to occur simultaneously.

The modification by Gould (1961) allows for simultaneous inflows and outflows, seasonality of flows and serial correlation of inflows. This was done by using a transition matrix of a yearly time period, but accounting for within-year flows by using behavioural analysis. This method allows for the use of non-continuous flow records (which makes it suitable for semi-arid regions), sampling all years of data regardless of the historical sequence and as such is much less demanding on the data. Perhaps more importantly, the computed storage estimates are independent of the initial starting contents of the reservoir. The Gould method can prove to be a powerful tool. It has a number of advantages and can provide valuable information about probable behaviour.

Problems occur with implementing the probability matrix method when there is a lack of flow data. Normally a flow series can be generated based on a nearby raingauge or regionalisation procedure and a crude assumption about the likely runoff volume from this rainfall (Hortonian runoff usually assumed for semi-arid catchments).

The Gould probability matrix method has been applied successfully in many regions of Africa. Parks et al. (1989) applied the Gould method to catchments in Botswana for estimating the effect of rationing on the probability of failure of a reservoir. The authors outlined some practical considerations to its application. The method provides information on the annual and monthly probabilities of failure.

\section{Model description}

The model adopts the modified Gould probability matrix as outlined by McMahon and Mein (1978) and employs a modified Eqn. 1 to allow for siltation rates. The method is usually used before construction of a reservoir rather than afterwards. The required input includes:

1. Monthly evaporation calculated by a commonly used equation. In the absence of these estimates, if class A pan data with appropriate monthly correction factors are available, then these data can be used.

2. Monthly abstraction data based on information on areal 
extent of irrigation, irrigated crop types and other factors.

3. Inflow data should be given as a two dimensional array of inflow during a specific year and month.

4. Siltation data

5. Start month, Years (number of years of inflow data)

6. Assumed capacity of the reservoir.

McMahon and Mein (1978) gave a detailed procedure to calculate step by step the probability of failure. These steps can be summarised as follows:

1. Prepare the input data (items 1 to 6 as mentioned above).

2. Set up a tally sheet to construct the transition matrix (a 2-dimensional array). This is done by dividing up the reservoir into 20 (or more) equal volume zones (including exactly empty and exactly full).

3. Apply the continuity equation (Eqn. 1) on a monthly basis for reservoir balance starting the reservoir in each of 20 zones and for each of the years of monthly data available and tally the number of times the reservoir "ends up" in each of the zones. Divide each column by $\mathrm{Nx} \mathrm{K}$ where $\mathrm{N}$ is the number of years of data and $\mathrm{K}$ is the number of zones.

4. Count the number of times (and number of months) the reservoir fails for each of the starting zones. As there is a total of $12 \mathrm{~N}$ months routed through each zone, the values may be converted to probability by dividing each entry by $12 \times \mathrm{N}$. This step is different from the original Gould method where the failure was defined on an annual basis.

5. Compute the steady state matrix by any technique. The "power up" technique has been chosen whereby the matrix is multiplied by itself until it reaches steady state. An alternative is to use simultaneous equations. The steady state reflects the long term solution and is independent of starting contents.

6. Multiply the steady state probability of the reservoir being in a particular zone (step 5) with the probability of failure for that zone (step 4). The resulting sum is the probability of failure of the reservoir.
7. If the computed probability of failure does not equal to the design probability, choose a new capacity and try again.

\section{Results and discussion}

To illustrate the usefulness of the method, the modified Gould probability matrix method for likelihood of reservoir failure studies has been applied on El-Gouazine catchment, Tunisia.

Monthly raingauge data at Kairouan (monthly data are available from World Climate Disc, CRU, 1992 for the period 1900-1989) are used in this example, together with the Horton parameters derived for the El-Gouazine catchment based on the local gauges and a loss factor derived from the rainfall-runoff data recorded at El-Gouazine for 1994-1995. The evaporation figures were based on the Class A pan evaporation measurements available at the site while the abstraction figures were based on available local information. Figure 1 shows the average monthly rainfall based on the 1900-1989 data record while Fig. 2 shows the estimated average monthly runoff from the 1900-1989 rainfall data record. Table 1 gives the average monthly evaporation, E, as estimated from Class A pan and the average monthly abstraction, Abs.

An example of model input window of HYDROMED model is shown in Fig. 3.

HYDROMED was run with different starting months to calculate the probability of failure. Four months were selected for illustration as shown in Fig. 4. It can be seen that the probability of failure differs from January, where possibly the supply is greater than the demand, compared with June, where the demand is greater than the supply. Generally, the probability of failure approaches zero at a capacity of $500,000 \mathrm{~m}^{3}$. The $25 \%$ probability of failure (75\% success) could be achieved with a reservoir capacity of $58,000 \mathrm{~m}^{3}$ in June and $95,000 \mathrm{~m}^{3}$ in January. The probability of failure at capacity of $240,000 \mathrm{~m}^{3}$ (close to storage capacity of El-Gouazine 233, $000 \mathrm{~m}^{3}$ ) is around $5 \%$ in November, December and January; around $3 \%$ in March, and around $1.1 \%$ in May and June. Consequently

Table 1. Average monthly evaporation and abstraction values of El Gouazine catchment.

\begin{tabular}{lllllllllllll}
\hline Month & Jan. & Feb & Mar. & Apr. & May & Jun. & Jul. & Aug. & Sep. & Oct. & Nov. & Dec. \\
E mm & 201 & 230 & 230 & 259 & 287 & 287 & 259 & 230 & 230 & 201 & 173 & 172 \\
Abs m $^{3} \times 10^{3}$ & 0 & 0 & 8 & 10 & 12 & 15 & 0 & 0 & 0 & 0 & 0 & 0 \\
\hline
\end{tabular}

Irrigation is assumed to take place only during the required part of the growing season. The total catchment area is 1810 ha and the reservoir capacity is $233 \times 10^{3} \mathrm{~m}^{3}$. 


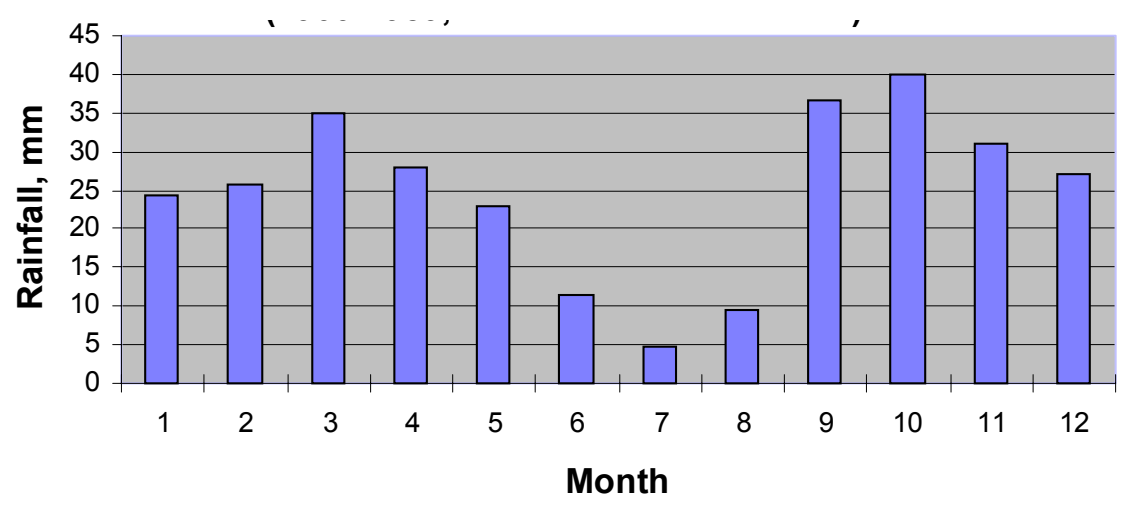

Fig. 1 Average monthly rainfall at Kairouan (1900-1989 World Climate Disc data)

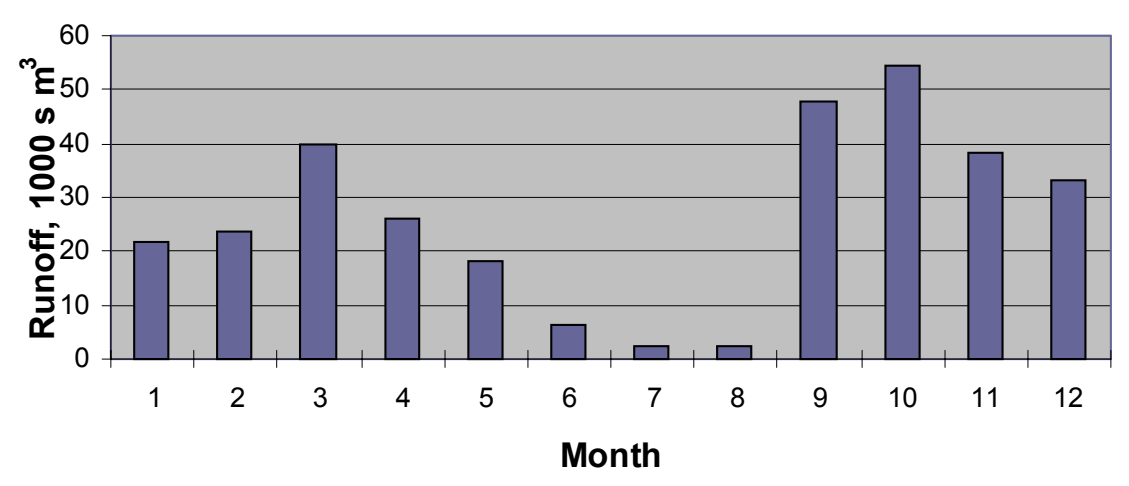

Fig. 2. Estimated monthly runoff at El-Gouazine, Tunisia (from Kairouan rainfall).

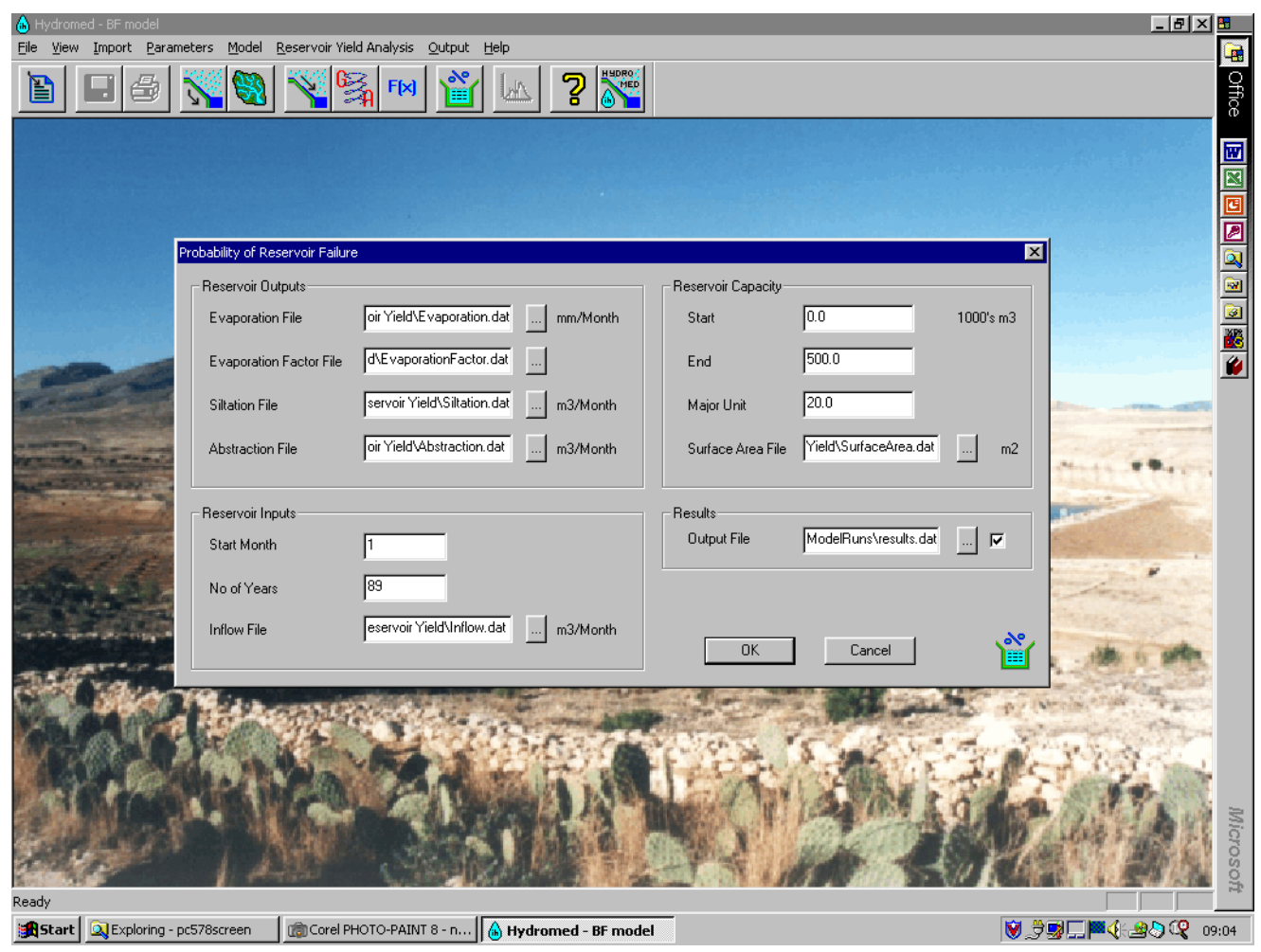

Fig. 3. Input windows for calculation of the probability of failure 


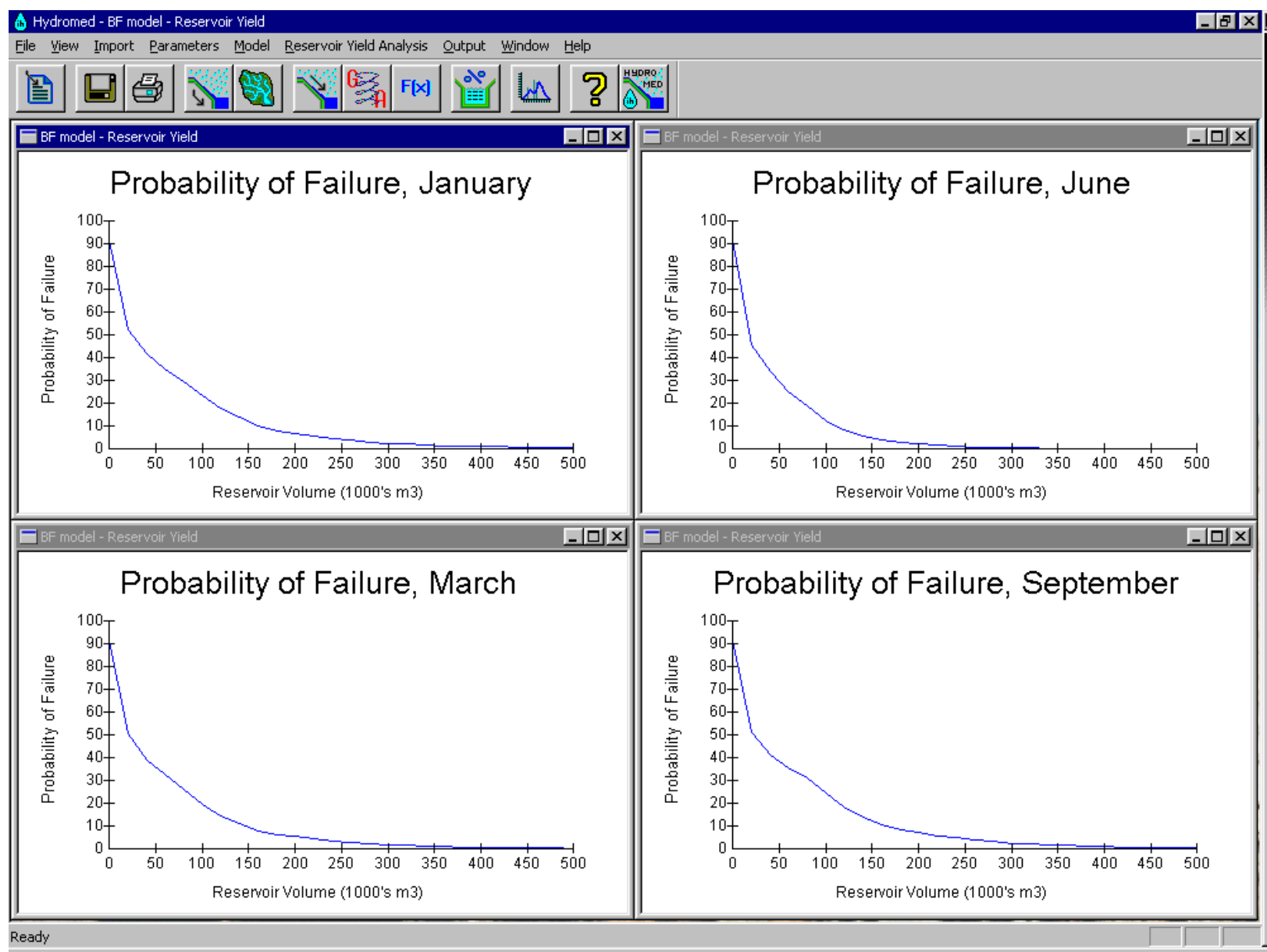

Fig. 4. Reservoir probability of failure at El-Gouazine, Tunisia for different times of the year.

there is no high risk of El-Gouazine not being able to meet its requirements at a capacity of $233,000 \mathrm{~m}^{3}$. In such a case, the benefits of increasing the reservoir volume above the $250,000 \mathrm{~m}^{3}$ are not very high. This is important knowledge for the design engineers and the funding organizations.

One should remember that this analysis is based on the data to hand, which might not be accurate enough. One also should consider that the effects of erosion and silting, which affect the storage capacity of the reservoir, are missing at present. However, silting rate data can be included in the calculation as and when they become available. Where the problems of erosion are combined with siltation, estimation of the probability of failure of a reservoir becomes more complicated. Estimating the likely rate of siltation of a reservoir is difficult because the rate of erosion increases exponentially with the rate of rainfall. At the extreme end, and as has been seen on catchments in Tunisia, reservoirs have become completely full of silt from only one rainfall event. If a standard rate of siltation (by volume) of the reservoir is assumed, then an appropriate adjustment can be made when consulting the probability of failure versus capacity graph on a year-by-year basis. Climate change and its impact should be considered when designing new reservoirs. The climate change scenarios suggest that the Mediterranean region will become hotter and drier.

\section{Conclusions}

The HYDROMED model has successfully implemented a modified Gould probability matrix method. The probability of failure has been calculated on a monthly basis for the ElGouazine catchment in Tunisia using a long data record from Kairouan. Estimation of the probability of failure has been obtained for different months of the year. Generally, the probability of failure approaches zero at a reservoir capacity of $500,000 \mathrm{~m}^{3}$. The $25 \%$ probability of failure ( $75 \%$ success) could be achieved with a reservoir capacity of $58,000 \mathrm{~m}^{3}$ in June and $95,000 \mathrm{~m}^{3}$ in January. The probability of failure of a reservoir of $240,000 \mathrm{~m}^{3}$ capacity (close to the storage capacity of EL-Gouazine 233, $000 \mathrm{~m}^{3}$ ) 
is approximately 5\% in November, December and January; $3 \%$ in March, and $1.1 \%$ in May and June. Consequently there is no high risk of El-Gouazine not meeting requirements at a capacity of $233,000 \mathrm{~m}^{3}$. Benefits, in terms of probability of failure, by increasing the reservoir volume greater than $250,000 \mathrm{~m}^{3}$ mark are not so high. This is important knowledge for the design engineers and the funding organizations. The method used here has the advantage of sampling all years data without reference to the sequence and therefore is particularly suitable for a catchment with patchy data. However one should bear in mind that the present analysis is based on the existing water abstraction policy, absence of siltation rate data and on the assumption that the present climate will prevail during the lifetime of the reservoir.

\section{Acknowledgements}

The HYDROMED model is part of the HYDROMED project, $50 \%$ funded by the European Union, EU and 50\% funded by the Natural Environment Research Council, UK. Thanks are due to Dr. Jean Albergel of IRD mission in Tunisia, the Co-Ordinator of the HYDROMED project for his support and to our partners of the HYDROMED project, ACSAD, Syria, INGREF, Tunisia, IAV Morocco for their cooperation.

\section{References}

Atkinson, E., 1998. Reservoir operation to control sedimentation: techniques for assessment. In: The prospect for reservoirs in the $21^{\text {st }}$ century, P. Tedd (Ed), Thomas Telford Ltd, London, UK. 226-241.

CRU., 1992. World Climate Disk, Global Climatic Change Data, Climate Research Unit, University of East Anglia, Norwich. UK. CD distributed by Chadwyck-Healey, Ltd., UK.

Gould, B.W., 1961. Statistical methods for estimating the design capacity of dams. J. Inst. Eng. Australia, 33, 405-416.

McMahon, T.A. and Mein, R.G., 1978. Reservoir capacity and yield. In: Developments in Water Science, V.T. Chow, (Ed.), 9, 71-106. Elsevier, Oxford, UK.

Meigh, J., 1995. The impact of small farm reservoirs on urban water supplies in Botswana. Natur. Resour. Forum. 19, 71-83.

Moran, P.A.P., 1959. The theory of storage. Methuen, London, UK.

Morel-Seytoux, H.J., 1999. Optimal Deterministic Reservoir Operations in Continuous Time, J. Water Resour. Plan. Man. 125, 126-134.

Parks, Y.P. and Gustard, A., 1982. A reservoir storage yield analysis for arid and semiarid climates. Optimal Allocation of Water Resources, 49-58. IAHS Publication No. 135, Wallingford, UK.

Parks, Y.P., Farquharson, F.A.K. and Plinston, D.T., 1989. Use of the Gould probability matrix method of reservoir design in arid and semi-arid regions. In: Proceedings of the Sahel Forum on The State-of-the-Art of Hydrology and Hydrogeology in the Arid and Semi-Arid Areas of Africa, M. Demissie and E. Stout (Eds.) 129-136, IWRA, Urbana, Illinois, USA.

Prinz, D., 1995. Water harvesting in the Mediterranean environment: it's past role and future prospect, Water Resources Management under Drought or Water Shortage Conditions, 135-144 , Balkema, Rotterdam, The Netherlands.

Tate, E.L. and Farquharson, F.A.K., 2000. Simulating reservoir management under the threat of sedimentation: The case of Tarbela Dam on the river Indus, Water Resour. Manag., 14, 191-208.

Tedd, P., Dutton, D.P.M. and Holton, I.R., 1998. Investigating internal erosion at Brent Dam. In: The prospect for reservoirs in the $21^{\text {st }}$ century, P. Tedd, (Ed.), Thomas Telford Ltd, London, UK. 70-78.

Vedula, S. and Kumar, D.N., 1996. An integrated model for optimal reservoir operation for irrigation of multiple crops, Water Resour. Res., 32, 1101-1108. 